\title{
Fallacious argumentation in student reasoning: Are there benefits?
}

\author{
Mary Mueller ${ }^{1}$ and Dina Yankelewitz2,* \\ ${ }^{1}$ Educational Studies, Seton Hall University, South Orange , USA \\ 2,*Childhood Education, Mercy College, Dobbs Ferry, USA \\ For correspondence: muellermf@shu.edu
}

\begin{abstract}
:
This article reports on an analysis of episodes of invalid or controversial arguments that occurred while two different groups of students worked on similar fraction tasks and examine the role that these types of arguments played in the development of students' reasoning. One group consisted of suburban, middle-class, fourth graders who worked on these tasks during the regular school day. The other group was comprised of sixth-graders from an urban community working on similar tasks as part of an informal learning after-school project. The findings of this study indicate that allowing students to share and discuss incorrect arguments promoted rich mathematical discourse and argumentation. The invalid arguments triggered the use of varied reasoning by other students and cleared up previous [mis]understandings.
\end{abstract}

Keywords: Mathematical Reasoning, Argumentation, Misconceptions, Collaboration, Discourse.

\section{Introduction}

Researchers generally agree that reasoning and proof are the basis of mathematical understanding, and that learning to reason and justify is critical for growth in mathematical knowledge (Polya, 1981; Hanna, 2000; Maher, 2009). Thompson (1996) defines mathematical reasoning as "purposeful inference, deduction, induction, and association in the areas of quantity and structure" (p.267). Yackel and Hanna (2003) extend this definition to recognize the social aspects of reasoning and describe it as a communal activity in which learners participate as they interact with one another to solve (resolve) mathematical problems (p.228). According to the National Council of Teachers of Mathematics (2000), the ability to reason is "essential to understanding mathematics" (p. 56). Reasoning is a process that enables the revisiting of ideas and can trigger the re-construction of previous knowledge in order to build new arguments (Davis, 1992; Maher, 2009). Therefore, reasoning and justification of arguments are not only essential to learning new mathematics, but are necessary to relate mathematical knowledge to other circumstances. Furthermore, reasoning and justification are the foundation of problem solving.

Unfortunately, students struggle with reasoning and justification. One explanation is that they are often not afforded opportunities to engage in problem-solving activities that encourage the development of reasoning skills. Mathematics instruction often focuses on the learning of mathematics facts and procedures and on learning skills and procedures needed to solve routine problems (Silver, Alacaci, \& Stylianou, 2000, p. 339). This approach inhibits children's building of natural, experience-based understandings and requires students to adapt their reasoning styles to fit those valued by schools (Malloy, 1999). Furthermore, the approach that ignores sense making often results in the building of cognitive obstacles or "improperly chosen assimilation paradigms that lead to incorrect ways of thinking or that are limited in their scope" (Davis, 1992, p. 226). Often, teachers do not allow students to share their misunderstandings in group discussions and instead present only correct strategies and solutions. (Santagata, 2005; Silver, Ghousseini, Gosen, Charalambous, \& Strawhun, 2005). In this case, students' misunderstandings may hinder their ability to reason and impede mathematical understanding. 
More recent work has shown that when given opportunities to engage in problem solving investigations involving rich mathematical discussion, young children can make conjectures and justify their claims with sound arguments if they are supported in the classroom and afforded opportunities to reason collaboratively (Francisco, 2005; Francisco \& Maher, 2005; Maher, 2002, 2009; Maher \& Martino, 1996; Maher, 2009). Yackel and Hanna (2003) stress that given a supportive environment, all students, as early as elementary school, can and do make and refute claims and participate in inductive and deductive reasoning.

Research suggests that allowing students to share and discuss errors can kindle students' mathematical thinking about concepts and procedures and thus promote reasoning in the classroom (Borasi, 1994; Kazemi \& Stipek, 2001). Mathematics education researchers contend that there is value in examining students' fallacious arguments (Borasi, 1994; Radatz, 1979). These studies show that erroneous arguments are an unavoidable and vital part of learning and give insight into how learners, in dealing with each other's arguments, can construct deeper understanding and build new knowledge (Barody \& Ginsberg, 1990). This study attempts to build on this research by examining how controversial reasoning or misunderstandings voiced by students in mathematics classrooms triggers discussions and how it affects the subsequent mathematical argumentation that take place. Importantly, this research traces the role of erroneous reasoning in the building and expansion of students' mathematical understanding, their use of correct and varied forms of reasoning, their engagement in the doing of mathematics, and the co-construction of arguments.

\section{Review of the literature}

The study reported in this article involved students working collaboratively on open-ended problem solving tasks. The students built models, created conjectures and defended these conjectures in an established mathematical community. They were invited to share their reasoning and justifications in small groups and whole class discussions. The established social norms were a necessary component of students feeling safe in sharing their own ideas and conjectures and in challenging the ideas of others. Following this is a brief discussion of current literature on problem solving tasks and mathematical communities that support reasoning, and the role of fallacious reasoning.

\section{Mathematical Communities that Support Reasoning.}

The current reform agenda focuses on engaging students in collaborative problem solving in discourse-rich learning communities in which students can engage in discussions and feel safe sharing and discussing their ideas, strategies and solutions with others (National Council of Teachers of Mathematics, 2000). Researchers contend that mathematical discussion within a learning community is an essential component in the development of mathematical reasoning and understanding (Forman, 2003; Lampert and Cobb, 2003; Yackel \& Cobb, 1996). According to Goos (2004), communities of mathematical inquiry are established when students are given opportunities to participate in mathematical discussion, propose and defend arguments, and challenge the ideas of their classmates.

According to Cobb, Yackel, and Wood (1995), established social norms, including those that are related to mathematical reasoning and argumentation, are crucial in creating an effective mathematical community. Furthermore, mathematical reasoning is advanced when these social norms are established and students are given opportunities to work together on open-ended tasks and encouraged to take ownership of their ideas and conjectures (Francisco and Maher, 2005). Through the sharing of ideas and strategies students build on and extend the ideas of others and further thier own mathematical thinking and understanding.

The social culture created in mathematical communities not only promotes diverse ideas and strategies but also celebrates errors and views them as learning opportunities (Stipek et al., 1998). In such communities, students are arbitrators of right or wrong, rather than the textbook or the teacher. Studies have shown the importance of inviting students to explain and comment on each other's strategies' and compare them to their own in developing strategies (Stein, Engle, Smith, \& Hughes, 2008). Research shows that the social norm of giving students opportunities to examine incorrect 
solutions in whole class discussion promotes mathematical thinking and conceptual understanding (Kazemi \& Stipek, 2001; Leinhardt \& Steele, 2005).

Collaborative Building of Ideas.

Building on the concept of co-acting (Martin, Towers, and Pirie, 2006), Mueller (2009) differentiates co-construction from integration. Co-construction occurs when learners collaboratively build an argument from conception, and integration occurs when an initial argument offered by one student is reinforced by input from another student as the student assimilates these ideas into his or her own schema. Mueller (2009) found that the process of integration of ideas greatly enhanced student reasoning and that in expanding on arguments offered by classmates, students offered varied forms of reasoning and strengthened individual arguments. Mueller, Yankelewitz, \& Maher (2011) extend that framework to include modification, and show that different forms of collaboration played distinct roles in influencing the resulting mathematical reasoning and argumentation.

Mueller, Yankelewitz, and Maher (2010a) suggest that when given opportunities to independently build their own schemas, through collaboration, students can resolve misconceptions without the assistance of a teacher. Thus, by encouraging students to rely on their own reasoning skills and that of their classmates, errors can become stepping stones to increased understanding and sense making (Mueller, Yankelewitz, \& Maher, 2010a).

Problem Solving Tasks

Mathematical problem solving tasks play a vital role task in sustaining student engagement in problem solving and promoting mathematical reasoning (Francisco \& Maher, 2005). Presenting students with challenging tasks facilitates mathematical reasoning and leads to mathematical understanding. This reasoning and understanding is furthered and students' problem solving obstacles are overcome when tasks are presented as strands of related problems that are revisited overtime and in different contexts (Francisco \& Maher, 2005). According to Koellner, Pittman, and Frykholm (2008), reasoning is furthered when students are given opportunities to work on openended tasks with many entry points, encouraged to visualize and build concrete represenations of problem situations, and invited to work collaboratively. Doerr and English (2006) suggest that tasks be designed to engage students in important mathematical problem situations such that their representations and justifications offer insight into their mathematical thinking. In addition, they suggest that tasks should allow for students to self-evaluate their solutions and reflect on their own reasoning.

Henningsen and Stein (1997) distinguish certain task characteristics that promote student reasoning and understanding, including opportunities for multiple representations, multiple solution approaches, and mathematical communication. In addition, they recommend that in order encourage high level mathematical thinking and engagement, certain classroom support factors must be present. These factors include tasks designed to build on students prior knowledge and experiences, an appropraite amount of time for discussion and the development of multiple strategies, and the opportunity to share higher level thinking and solution strategies.

Fallacious Reasoning.

According to Skemp (1971) “...to understand something is to assimilate it into an appropriate schema" (p. 45). Thus, a student's level of understanding is dependent upon the schema that they create. Understanding develops as students form connections between new and old knowledge and create appropriate schemas to make sense of new knowledge (Maher \& Martino, 1996). However, students' prior erroneous knowledge may impede this process (Mueller, Yankelewitz, \& Maher, 2010a). Students' schemas develop over many years and are often difficult to change (Zeidler, Lederman, \& Taylor, 1992). Zeidler, Lederman, \& Taylor (1992) define a fallacy (or fallacious reasoning) as "any argument that purports to be correct and is psychologically persuasive but that proves, upon scrutiny, to have violated some rule of logic which renders it incorrect" (p. 440). They 
contend that fallacious reasoning cannot be corrected using direct instruction as this most often leads to resistance or is simply ineffective.

Borasi (1996) suggests that students' fallacious arguments can promote mathematical understanding, contending that errors motivate students to pursue open-ended explorations. He argues that teachers generally punish, ignore, or correct students' faulty thinking and claims that some even consider paying attention to erroneous solutions as hazardous in that it could interfere with students understanding of the "correct" concepts. Countering this notion, he suggests that errors (including contradictions, tentative hypothesis, contrasting results and unreasonable results) can invite openended explorations and be used as "springboards for inquiry". Borasi asserts that purposely engaging students in activities that promote use of invalid arguments can facilitate learning opportunities including realizing doubt and conflict, pursuing exploration, engaging in challenging problem solving, monitoring and defending arguments, taking initiative and ownership, and communicating mathematically.

In order to facilitate the use of invalid arguments to support deeper reasoning, it is important to identify common causes of students' mathematics misunderstandings. One cause that may impede mathematical reasoning is negative transfer (Radatz, 1979). Often, students use previously developed rules and procedures even when the structure or conditions of the task have changed (Mueller, Yankelewitz, \& Maher, 2010a). Radatz suggests that another origin of faulty reasoning is the application of irrelevant rules or strategies. According to Ginsberg (1977), "often children think of mathematics as an isolated game with particular sets of rules and no evident relation to reality ....at the same time, children's faulty rules have sensitive origins" (p. 128). A case study of this phenomenon is described in Erlwanger (1973). In a study of sixth grade students, Mueller, Yankelewitz, and Maher (2010a) found that students had misconceptions about previously learned fraction rules and these misconceptions hindered their learning of fraction concepts and relationships. Kamii and Diminck (1998) argue that teaching rules and conventions can be harmful, because they cause children to relinquish their own ideas, which may also be mathematically sound, and disconnect the content from the concepts. When exposed to this kind of instruction, students often remember and later apply erroneous rules and procedures.

This article reports on an analysis of episodes of controversial arguments that occurred while two different groups of students were working on similar tasks involving fractions and examine the role that these controversial arguments played in the development of the students' reasoning. One group consisted of suburban, middle-class, fourth graders during the regular school day. The other group consisted of sixth-graders from an urban community working on similar tasks as part of an informal learning after-school project. Previous research has documented that both groups used varied forms of reasoning to defend and counter claims proposed during the mathematical discussions that took place (Maher, 2009; Yankelewitz, Mueller, \& Maher, 2010a; Mueller, Yankelewitz, \& Maher, 2010b). More specifically, the purpose of this study is to examine the following: What role, if any, do erroneous arguments/solutions play in students' reasoning when collaboratively attending to openended mathematical tasks?

\section{Methods and data source}

\section{Participants.}

Research for this study draws on data from two sources. The first is a researcher-conducted longitudinal study of students' mathematical thinking in a fourth grade classroom in a suburban/rural school in New Jersey. The class was composed of twenty-five students, fourteen girls and eleven boys between the ages of nine and ten. The entire intervention occurred over fifty sessions during the school year. During approximately half of the sessions students explored fraction ideas using manipulative materials, including Cuisenaire rods.

The second data source is an informal after-school math program consisting of twenty-four sixth grade students between the ages of twelve to thirteen. This study was conducted by researchers in a 
low socioeconomic, urban community in New Jersey, drawn from a school consisting of $99 \%$ Latino and African American students . The study was part of a voluntary, after-school program that met twice week and engaged the students in working on strands of open-ended math tasks. During the first eight sessions of the after-school program, the students worked on fraction tasks and were invited to explore fraction relationships using Cuisenaire rods.

\section{Data Collection}

We report on data from the first seven 60 minute sessions of the first study and the first five 60-75 minute sessions of the second. In both studies, the students were seated in heterogeneous groups of four in the sixth grade study and pairs in the fourth grade study and invited to work collaboratively with their group. In order to promote collaboration, students were posed open-ended tasks, encouraged to share their thinking with their group members, the researchers, and the class, invited to defend their arguments and challenge those of others, and given enough time to explore and create their solutions (Mueller, Yankelewitz, \& Maher, 2010b).

Both groups of students worked on similar tasks involving fraction as number, fraction equivalence, and fraction comparison. Cuisenaire ${ }^{\circledR}$ rods were available to the students during the sessions. A set of Cuisenaire rods (see Figure 1) contains 10 colored wooden or plastic rods that increase in length by increments of one centimeter. For the activities presented in the intervention, the rods were given variable number names and permanent color names. Students quickly learned to create rods of different lengths by placing rods along side each other and making a 'train'. Figure 2 shows a 'train' of a purple and an orange rod.

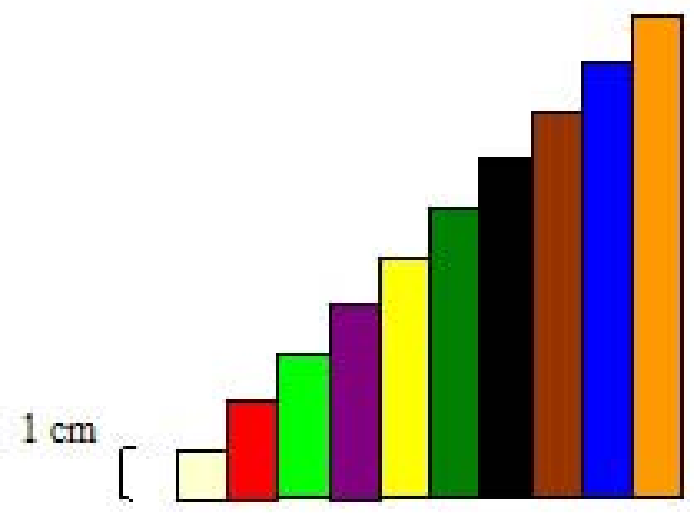

Figure 1. Staircase model of Cuisenaire rods.

\section{Purple}

Figure 2. A train of an orange and purple rod.

The tasks in both studies were from a strand on fractions. These tasks were first used in the fourth grade longitudinal study and found to promote collaboration among students (Maher. 2002). In addition, the rich justifications that students developed while attending to the tasks generated varied forms of reasoning (Mueller and Maher, 2009). Due to the richness in dialogue and reasoning found during student work on the tasks, the researchers began the after-school program sessions using a set of tasks from the fourth grade strand. It is important to note that the students in the fourth grade investigated these tasks before being formally introduced to fractions in the school curriculum; conversely, the sixth grade students were introduced to fraction procedures and rules in the previous year during their regular math instruction. However, the research team realized early in the sessions that the students lacked conceptual understanding of fraction ideas, relationships, and operations, and, as has been noted in the literature cited above, the students' prior knowledge at times impeded their acquisition of the concepts introduced during the intervention. 
The students were given tasks to investigate and asked to find relationships. For example, during one of the sessions the researcher asked, "What number name would you give to the dark green rod if the light green rod is called one? Discuss the answer with your group" (Maher, 2002). Students were given time to work collaboratively, build models, and share their ideas/strategies in their small groups. After each task was posed and worked on, students shared their models, strategies, and solutions with the entire class. An overhead projector was used so that students could demonstrate their fraction models as they were explaining their findings. During the whole class discussions, students were encouraged to question the ideas of others and revisit and revise their own strategies/solutions.

Data Analysis.

Three data sources were used for this study: video recordings of each session, copies of student written work, and researcher field notes. For both classes, the series of sessions were videotaped with at least two cameras. Video recordings and transcripts were analysed by means of a modified ground theory approach using the analytical model adapted from Powell, Francisco, and Maher (2003). The video data were viewed, described at frequent intervals, transcribed, and critical events (episodes of reasoning and collaboration) were identified. The analytical model is used to study the development of mathematical thinking and contains the following seven interacting, non-linear phases: viewing the video data, describing the video data, identifying critical events, transcribing, coding, constructing a story line, and composing a narrative (Powell, Francisco and Maher, 2003; 2004). The video data were viewed, described at frequent intervals, transcribed, and critical events (episodes of reasoning and collaboration) were identified.

Based on the critical events, codes were developed for flagging for solutions offered by students and the justifications given to support these solutions. Arguments and justifications were coded according to the type of argument (whether it supported a claim or was a counterargument), and the form of reasoning being used (contradiction, cases, upper and lower bounds, recursive, or direct). Sub-codes were developed for incomplete arguments and to identify arguments as valid or invalid, based on whether or not the argument started with appropriate premises and the deductions within the argument were a valid consequence of previous assertions. The latter two data sources were used to triangulate the data and to provide further evidence and detail to the critical events noted in the video data.

Students' construction of solutions and their subsequent justifications were traced across the data in an effort to document and analyse their journey to mathematical understanding. In both groups, students worked collaboratively on problem solving tasks. As a result, we also traced the joint construction of arguments in an attempt to analyse the ways in which students integrated the ideas of others into their justifications and solutions. Codes for the co-construction of ideas emerging from the analysis of the data were organized into the following categories: building on other's ideas, questioning others, and correcting others. In the initial analysis of both data sets, we found that students often corrected and/or challenged each other's solutions and/or arguments while working on the tasks. These corrections often took the form of counter-arguments. As can be expected, we noticed that a large percentage of these counter-arguments were posed after a faulty argument was made. Interestingly, whereas the majority of arguments posed took the form of direct reasoning, much of the varied reasoning that was noted resulted in discussions that followed a faulty argument. After noting these trends, we began a more systematic study of the effect of the faulty arguments on the subsequent forms of reasoning that were elicited. Below, we trace the kinds and variety of reasoning that resulted during a conversation powered by a faulty argument offered in the classroom.

\section{Results}

While attending to the fraction tasks, students built arguments and counterarguments taking the form of direct reasoning, indirect reasoning, cases, upper and lower bounds, and recursion. While working on most tasks, students used direct arguments to justify their solutions. We identified sessions and 
tasks during which students used multiple forms of reasoning, or during which students built arguments following several iterations and in response to the comments of other students. These occurrences highlighted instances of varied and complex argumentation, respectively. Analysis of both data sets highlighted that these situations were more often than not triggered by a fallacious or controversial arguments that led to varied argumentation and student engagement. In the following section we share episodes of erroneous reasoning that promoted mathematical discourse, cleared up previous [mis] understandings, and led to the co-construction of arguments.

Episode 1 Grade 6, Session 5, Naming Fractions.

The students were asked to name the white rod when the orange rod was named one. Herman used a model of ten white rods lined up next to the orange rod to incorrectly name the white rod ten (figure 3). Using direct (though faulty) reasoning, he explained that the orange rod is equivalent to ten white rods and therefore the white rod would be named ten. The teacher/researcher asked the class if they agreed. Dante said that he disagreed with Herman and compared the task to a previous task to the task of naming the rods when the blue rod was named one. He explained that when the blue rod was named one, the white rod was named one-ninth (because the length of nine white rods is equivalent to the length of a blue rod). He then explained that when the orange rod was named one the white rod would be named one-tenth: "We used to say that the blue was one so I thought that if we called the white rod one-ninth, why can't we still call it with the orange rod one-tenth though cuz even though the orange rod is one white one bigger than it .....so like this is nine ...this is ten ..that's why I think it should be called one-tenth, I think it should be called one-tenth". Thus, Dante used a counterargument and indirect reasoning to name the white rod one-tenth. He built his argument on a previous task of naming the white rod one-ninth when the blue rod was named one.

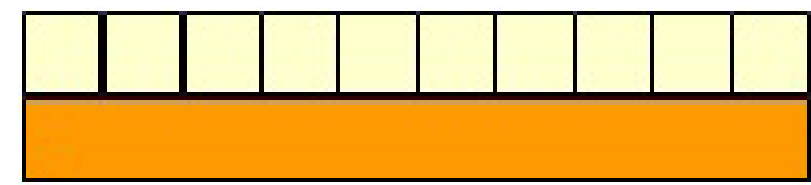

Figure 3. Ten white rods lined up against the orange rod.

When Herman still disagreed, Dante said that he could "prove it" and used Herman's model and direct reasoning to explain, "See you need ten of these [white] to equal one orange rod. If we take nine of them away which will leave you with one-tenth and then if you add another one it will be two-tenths, three-tenths all the way up to ten, which is a whole". Herman agreed and was able to explain in his own words, "Each one of these [white rods] equals one-tenth if this [orange rod] is one whole". In order to further check Herman's understanding, the teacher/researcher extended the task and asked students to name the orange rod if the white rod was given the number name of ten. Dante replied one-hundred and Herman explained, "Because there will be ten and ten times ten equals 100".

The teacher/researcher asked if the class was convinced that the white rod would have the number name one-tenth if the orange rod was called one. Lorrin agreed and explained using direct reasoning that when the blue rod is named one, the white rod is named one-ninth because the length of nine white rods is equivalent to the length of a blue rod. She said that the blue rod is "one size smaller" than the orange rod. During that session, three more students shared similar justifications of the solution.

Episode 2: Grade 6, Session 5, Finding Equivalent Fractions.

During the sixth session of the after-school program, the orange rod was called the number name one and students named the red rod one-fifth. A student noted that the length of the white rod is one-half the length of the red rod. He said that members of his group claimed that another name for the red rod is two-tenths. The teacher/researcher asked the class if they thought all, some, or none of these statements were true. 
Using direct reasoning, Chris said, "It's true because if ten white ones [rods] equal an orange one [rod], five red ones equal an orange one and the red one is one-fifth". Chanel agreed with the part about the white and red rods, explaining that the length of two white rods is equivalent to the length of a red rod. She then stated that if one of the white rods is taken away, the other white rod would be half of the red rod. She concluded, using faulty reasoning, that the red rod would be called one half.

The teacher/researcher asked for the class's opinion about Chanel calling the red rod one-half (when the orange rod is called one) and Dante disagreed. He used a direct counterargument to explain that the length of the red rod could not be half the length of the orange rod because the length of the yellow rod is half of the length of the orange rod. He asked, "How could red be a half of orange if it takes five of them instead of two?" Dante stated that he thought the red rod would be two-tenths and asked the class to pretend that the orange rod was named one-hundred. He said that the red rod would then be named twenty. He explained that, since the orange rod is equivalent to five red rods, "it would be twenty times five which would equal a hundred". He concluded that the red rod would be named two-tenths, explaining, "I think that red would be two-tenths because two times, cuz you need five reds to make the orange one, so two times five would equal ten so that's why I think it would be two-tenths".

The teacher/researcher asked if the class agreed and multiple students voiced agreement. Addressing Chanel's error, she then asked what number name the red rod would have in order for the white rod to be named one-half. Shanae said one and explained, "Because two white rods equal a red rod."

\section{Episode 3: Grade 4, Session 6, Comparing Fractions.}

During the sixth session in the fourth grade class, the teacher/researcher asked the students to compare one half and one fourth. Amy, Jacquelyn, and James built the model at the OHP (Figure 4) and Amy explained that in their model, the brown rod was called one, the purple rods were one half, the red rods were one quarter, and the white rods were one eighth. James then said, using faulty reasoning, that one half was larger than one quarter by one eighth.

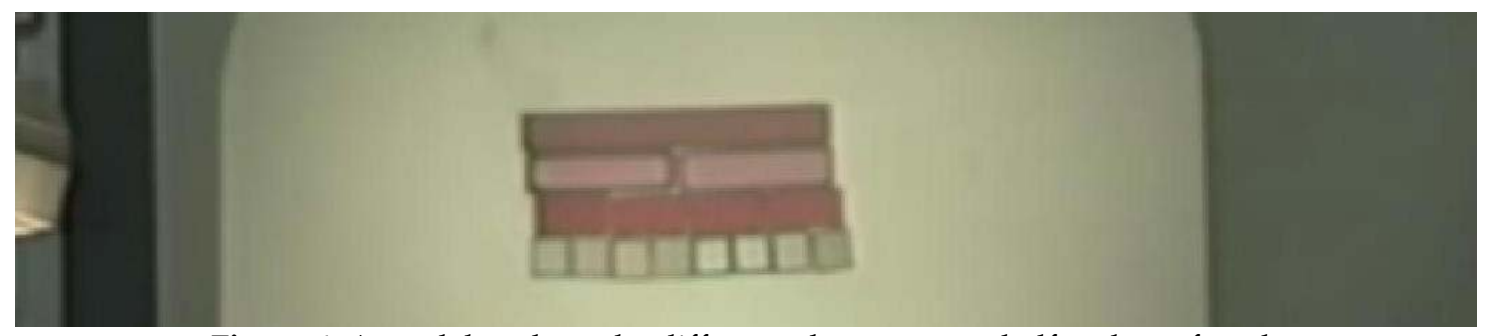

Figure 4. A model to show the difference between one half and one fourth

Meredith countered the team's argument. She asked them if they were calling the white rod one eighth, and they answered that they were. She then built a model of one purple rod and a train of one red and one white rod (Figure 5). Using indirect reasoning, she explained that the group's solution could not be correct, "because there is still negative space" on the model. Adding a second white rod onto her model to fill that space, she called the difference two eighths and then substituted a red rod for the two white rods and renamed that length one quarter.

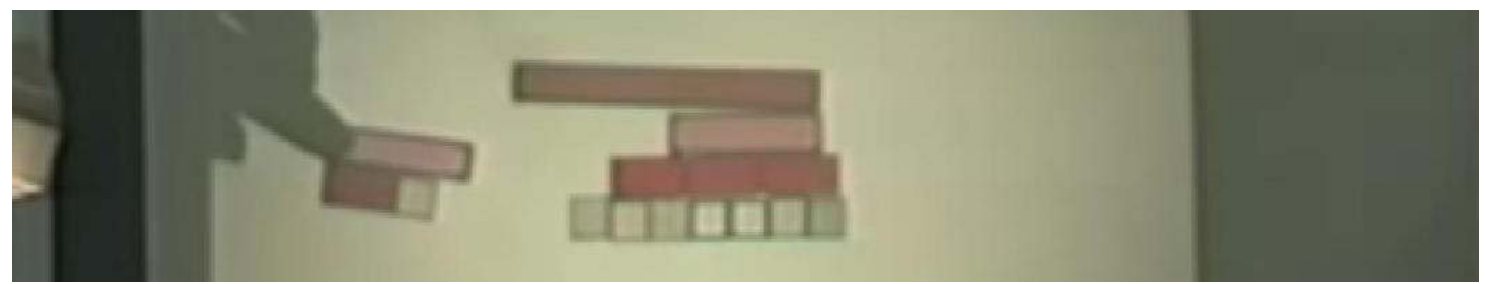

Figure 5. Meredith's model 
The teacher/researcher asked the three students what they thought of Meredith's argument. Jacquelyn said, "Well, I think we meant that all these put all together are one eighth". Meredith asked if they meant that two white rods were one eighth. Jacquelyn clarified, "We thought, uh, all of these whites put together were one eighth". Although Jacquelyn used faulty reasoning to revise the argument, she made its flaws more explicit. In response, Meredith moved the train of eight white rods onto her original model. She asked rhetorically, "You think it's bigger than one eighth and all these are one eighth? So that's how much you think it's bigger by?" Jacquelyn laughed. Here, too, Meredith used indirect reasoning to show that their claim could not be true.

Jacquelyn then revised her argument, saying that one half was larger than one quarter by two eighths or one quarter. The teacher/researcher questioned how she knew that it could be one quarter, and Jacquelyn responded that the red rods were each one quarter. Since the two white rods were the same length, they could also be named one quarter.

\section{Discussion}

The results of this study indicate that affording students opportunities to share and discuss incorrect arguments promoted mathematical discourse and argumentation (Stein, Engle, Smith, \& Hughes, 2008). As suggested by Borasi (1996), when the students presented controversial arguments, the other members of the community were engaged in correcting their arguments through counterarguments and thus further pursued their open ended exploration. These counterarguments led to sophisticated reasoning and cleared up [mis] understandings. Furthermore, while responding to invalid arguments students were engaged in monitoring and defending arguments, taking initiative and ownership, and communicating mathematically (Borasi, 1996). In addition, erroneous arguments afforded individual students the opportunity to make their reasoning explicit, and thereby correct their own reasoning. The data show that as students worked to convince their classmates of the error of an argument, they persistently refined and strengthened their counterarguments. In these ways, both the originators of the faulty arguments and their classmates refined their reasoning during the discussions. This supports the notion that the process of integration and modification of ideas leads to enhanced student reasoning and stronger arguments (Mueller, 2009; Mueller, Yankelewitz, \& Maher, 2011) and adds a third element of alteration of ideas to the framework.

The social norms that were created in the mathematical community supported the sharing of ideas and strategies (Stipek et al., 1998). By attending to classmates' faulty reasoning through counterarguments, the students explained their justifications more explicitly and offered clearer arguments. In addition, they often extended their reasoning and/or used varied arguments to support the correct solution. In episode 1, Dante had correctly named the white rod one-tenth. When Herman countered with an incorrect solution, Dante used indirect reasoning to explain his justification in order to help Herman understand his position. When Herman was still not convinced, Dante made use of Herman's model and used direct recursive reasoning and Herman's model to finally convince him. During this process, and as a result of Herman's misconception, Dante strengthened his original argument, used varied forms of reasoning to support his solution, and utilized multiple representations during his justification. In addition, Dante's argumentation moved away from simply responding to the task with the solution to considering the ideas of others while fortifying his justification. At the same time, Herman was able to build a correct schema and revise his own misconception. At the end of the session, Herman evidenced that he understood the solution and used sound reasoning to explain why the white rod was named one-tenth. In addition, Herman extended his reasoning and applied it to another example. Likewise, other classmates integrated and modified the arguments offered in the discussion and created their own varied justifications for the correct solution. As Mueller (2009) asserts, this integration led to diverse forms of reasoning. Thus by inviting students to attend to and discuss incorrect solutions, Herman's and other classmates' mathematical thinking and understanding was advanced (Kazemi \& Stipek, 2001; Leinhardt \& Steele, 2005).

In episode 2, Chris offered an incomplete direct argument to name the red rod one-fifth (when the orange rod was named one). When Chanel disagreed and incorrectly named the red rod one half, he 
then presented a detailed, direct counterargument using whole numbers in an attempt to convince Chanel. Dante extended Chris' argument, modified it, and used two kinds of reasoning, direct and indirect, to support his argument. The establishment of a mathematical community allowed for the sharing of errors and misconceptions and considered them as opportunities to further understanding (Stipek et al., 1998).

During episode 3 when comparing one-half to one-fourth Jacquelyn and James erroneously found the difference to be one-eighth. Meredith offered indirect reasoning and a direct counterargument in an attempt to show them their misunderstanding. When Jacquelyn again offered a faulty argument, Meredith used indirect reasoning with an extended model to convince her that her claim was impossible. As was seen in the first two episodes, the voicing of an incorrect solution allowed students to build on their own or other solutions, extend them, and use varied forms of reasoning in their argumentation. Thus, the students in these episodes relied on their own reasoning skills and that of their classmates and resolved misunderstandings without the assistance of a teacher (Mueller, Yankelewitz, and Maher, 2010a).

\section{Significance}

Teachers often attempt to avoid making erroneous solutions and arguments public, believing that others will be influenced by these arguments and, in turn, reason incorrectly (Borasi, 1996). The data from the study of fourth and sixth grade classrooms shows that the opposite occurred. The community was not "corrupted" by the incorrect ascertains, rather they used valid and substantiated reasoning to correct their classmates invalid claims. Furthermore, the errors were ultimately corrected in the whole class discussion, and the justification of the reasoning was articulated clearly for the benefit of all students. In addition, students extended and varied their arguments using complex forms of reasoning and alternate representations to make their understanding of the task accessible to their peers. In most cases, as has been evidenced, the originators of the faulty arguments and their classmates ably defended the correct solution after the discussion. In this way, the argumentation process enabled all the students to understand why the correct answer made sense.

The errors made by both groups are common errors that students consistently make in attempting to manipulate fractions. In the first episode, the student reverted to whole number schema, rather than fractional ones. In episodes 2 and 3 the students switched the unit, comparing a fraction length to another fraction length, rather than the original length of the unit. As stated in the literature review, these schemas develop over time are often difficult to adjust (Zeidler, Lederman, \& Taylor, 1992). The data suggests that making these arguments public leads to student-to-student questioning and correction and ultimately to the co-construction of arguments. Such co-construction is only possible when students listen carefully to the solutions of others. Although the students in the two studies were different ages, from different communities, and different settings, the mathematics environment in which they were engaged was very similar. The students were given open-ended tasks and afforded opportunities to build models, make claims, and support these claims. Throughout, they were the arbiters of what made sense. Knowing that the teachers/researchers would not correct erroneous solutions, they took the initiative. In addition, as described in the methodology, a community of learners was formed from the start, and the students were invested in each other's mathematical understanding.

As Borasi (1996), Kazemi and Stipek (2001), and Barody and Ginsberg (1990) contend, this study supports the notion that encouraging students to discuss misconceptions results in the construction of deep understanding and the development of mathematical reasoning. This current study has extended the research by uncovering its value in promoting the development of varied forms of reasoning, complex classroom argumentation, and the refinement of mathematical arguments and justifications. As students take on the challenge of defending a correct solution in the face of disagreement, they are forced to find novel approaches and multiple ways of representing their original understanding. During this process, all students benefit and, in most cases, emerge with a better understanding of the mathematical task. 
The implications of this study suggest that a learning environment that promotes the sharing of arguments, regardless of their mathematical validity, engenders student engagement in one another's ideas and results in the co-construction of sound arguments using varied forms of reasoning. Thus to facilitate mathematical reasoning teachers could consider allowing students to grapple with difficult tasks and share misunderstandings in a supportive environment. By allowing students to challenge and defend solution strategies, reasoning and sound justifications emerge. Consequently, to support students in building models, reasoning, and conjecturing, the role of the teacher shifts from being the arbitrator of right and wrong to facilitating students in defending and challenging arguments. Based on this study, if students are afforded the opportunity to build and defend their own models, solutions and strategies with minimal interventions and learn from their errors and the errors of others, they will make their own sense of the mathematics and develop understanding.

\section{Acknowledgements}

The research presented here is a component of two longitudinal studies:

REC 0309062, directed by Carolyn Maher, Arthur Powell, and Keith Weber, was funded by the National Science Foundation. The views expressed in this article are those of the authors and do not necessarily reflect the views of the NSF.

MDR 9053597, directed by Robert B. Davis and Carolyn Maher, and REC 9814846, directed by Carolyn Maher, was funded by the National Science Foundation. The views expressed in this article are those of the authors and do not necessarily reflect the views of the NSF.

\section{References}

Barody, A. J., \& Ginsburg, H. P. ( 1990 ). Children's mathematical learning: A cognitive view. In R. B. Davis , C. A. Maher, $\&$ N. Noddings ((Eds.), Constructivist views on the teaching and learning of mathematics (pp. 19-29). Reston, VA: National Council of Teachers of mathematics.

Borasi, R. (1996). Reconceiving mathematics instruction: A focus on errors. Santa Barbara ,CA: Greenwood Publishing Group. Cobb, P. Yackel, E., \& Wood, T. (1995).

The teaching experiment. In P. Cobb and H.Bauersfeld, (Eds.), The emergence of mathematical meaning: Interaction in classroom cultures (pp. 17-24). Hillsdale, NJ: Lawrence Erlbaum Associates.

Davis, R.B. (1992). Understanding “Understanding”. Journal of Mathematical Behaviour, 11, 225-241.

Erlwanger, S.H. (1973). Benny's conception of rules and answers in IPI mathematics. Journal of Children's Mathematical Behavior, $1(2), 7-26$.

Forman, E. A. (2003). A sociocultural approach to mathematics reform: Speaking, inscribing, and doing mathematics within communities of practice. In J. Kilpatrick, W. G. Martin, \& D.Schifter (Eds.), A research companion to principles and standards for school Mathematics (pp. 333-352). Reston, VA: National Council of Teachers of Mathematics.

Francisco, J. M. (2005). Students' epistemological ideas in mathematics: A 12-year longitudinal case study on the development of mathematical ideas. Unpublished doctoral dissertation, Rutgers, the State University of New Jersey, New Brunswick.

Francisco, J.M. \& Maher, C.A. (2005). Conditions for promoting reasoning in problem solving: Insights from a longitudinal study. Journal of Mathematical Behavior, 24, 361-372.

Ginsburg, H. (1977). Learning to Count. Computing with Written Numbers. Mistakes. In Ginsburg, H., Children's Arithmetic: How They Learn It and How You Teach It (pp. 1-29, 79-129).

Goos, M. (2004). Learning mathematics in a classroom community of inquiry. Journal for Research in Mathematics Education, 35 (4), 258-291.

Gresalfi, M., Martin, T., Hand, V. \& Greeno, J. (2009). Constructing competence: an analysis of student participation in the activity systems of mathematics classrooms. Educational Studies in Mathematics, 70, 49-70.

Hanna, G. (2000). Proof, explanation and exploration: An overview. Educational Studies in Mathematics, Special issue on "Proof in Dynamic Geometry Environments", 44 (1-2), 5 23. Copyright 2001.

Henningsen, M., \& Stein, M. K. (1997). Mathematical tasks and student cognition: Classroom-based factors that support and inhibit high-level mathematical thinking and reasoning. Journal for Research in Mathematics Education, 524-549.

Kamii, C. \& Dominck, A. (1998). The harmful effects of algorithms in grades 1-4. In L. J. Morrow \& M. J. Kenney (Eds), The teaching and learning of algorithms in school mathematics: 1998 yearbook. (pp130-140). Reston, VA: The National Council of Teachers of Mathematics.

Kazemi, E., \& Stipek, D. (2001). Promoting conceptual thinking in four upper elementary Mathematics classrooms. The Elementary School Journal, 102, 59-80.

Koellner, K., Pittman, M., \& Frykholm, J. (2008). Talking generally or generally talking in an algebra classroom. Mathematics Teaching in the Middle School, 14, 304-310.

Lampert, M. \& Cobb, P. (2003). Communication and language. In J. Kilpatrick, W.G.Martin, \&D. Schifter (Ed.s), A Research Companion To Principles and Standards for School Mathematics (pp 237-249). Reston, VA: NCTM.

Leinhardt, G., \& Steele, M. D. (2005). Seeing the complexity of standing to the side: Instructional dialogues. Cognition and Instruction, 23, 87-163. 
Maher, C.A. (2002). How students structure their own investigations and educate us: What we have learned from a fourteen year study. In A. D. Cockburn \& E. Nardi (Eds.), Proceedings of the Twenty-sixth Annual Meeting of the International Group for the Psychology of Mathematics Education (PME26) (Vol. 1, pp.31-46). Norwich, England: School of Education and Professional Development, University of East Anglia.

Maher, C. A. (2009). Children's reasoning: Discovering the idea of mathematical proof. In M. Blanton and D. Stylianou (Eds.), Teaching and learning proof across the grades. New Jersey: Taylor Francis - Routledge.

Maher, C. A., \& Martino, A. M. (1996). Conditions for conceptual change: From pattern recognition to theory posing. In H.

Mansfield \& N. H. Pateman (Eds.), Young children and mathematics: Concepts and their representation (pp. 58-81). Sydney, Australia: Australian Association of Mathematics Teachers.

Malloy, C. E. (1999). Developing mathematical reasoning in the middle grades: Recognizing diversity. In L.V. Stiff \& F.R. Curcio (Eds.), Developing mathematical reasoning in grades K-12 NCTM 1999 Yearbook (pp. 13-21). Reston, VA: National Council of Teachers of Mathematics.

Martin, L.C., Towers, J. \& Pirie, S.E.B. (2000) Growing Mathematical understanding: Layered observations. In M.L. Fernandez (Ed.), Proceedings of the Twenty-second Annual Meeting of the North American Chapter of the International Group for the Psychology of Mathematics Education, 1 (pp.225-230). Tuscan, AZ.

Mueller, M. (2009). The co-construction of arguments by middle school students. The Journal of Mathematical Behavior, 28 (2/3), 138-149.

Mueller, M., Yankelewitz, D. \& Maher, C. (2010a). Rules without reason: Overcoming students' obstacles in learning. The Montana Mathematics Enthusiast, 7(2).

Mueller, M., Yankelewitz, D. \& Maher, C. (2010b). Promoting student reasoning through careful task design: A comparison of three studies. International Journal for Studies in Mathematics Education, 3(1).

Mueller, M., Yankelewitz, D. \& Maher, C. (2011). Examining the role of agency in students' collaborative construction of arguments. Educational Studies in Mathematics, 80(3), 369-387.

National Council of Teachers of Mathematics, 3rd Ed. (2000). Principles and Standards for School Mathematics. Reston, VA: NCTM.

Polya, G. (1981). Mathematical discovery. New York: Wiley.

Powell, A., Francisco, J.M. \& Maher, C.A. (2003). An analytical model for studying the development of learners' mathematical ideas and reasoning using videotape data. Journal of Mathematical Behavior, 22, 405-435.

Radatz, H. (1979). Error analysis in mathematics education. Journal of Research in Mathematics Education, 10 (3), pp. 163-172.

Santagata, R. (2005). Practices and beliefs in mistake-handling activities: A video study of Italian and US mathematics lessons. Teaching and Teacher Education, 21, 491-508.

Silver, E.A., Alacaci, C. \& Stylianou, D.A. (2000). Students' performance of extended constructed-response tasks. In E.A. Silver \& P.A. Kenney (Eds.), Results from the seventh mathematics assessment of the national assessment of educational progress, (pp. 307343). Reston, VA: NCTM.

Silver, E. A., Ghousseini, H., Gosen, D., Charalambous, C., \& Strawhun, B. T. F. (2005).Moving from rhetoric to praxis: Issues faced by teachers in having students consider multiple solutions for problems in the mathematics classroom. Journal of Mathematical Behavior, 24, 287-301.

Skemp, R. R. (1971). The Psychology of Learning Mathematics. Penguin Books.

Stein, M. K., Engle, R. A., Smith, M. S., \& Hughes, E. K. (2008). Orchestrating productive Mathematical discussions: Five practices for helping teachers move beyond show and tell. Mathematical Thinking and Learning, 10, 313-340.

Stipek, D., Salmon, J. M., Givven, K. B., Kazemi, E., Saxe, G., \& MacGyvers, V. L. (1998). The value (and convergence) of practices suggested by motivation research and promoted by mathematics education reformers. Journal for Research in Mathematics Education, 29, 465-488.

Thompson, P.W. (1996). Imagery and the development of mathematical reasoning. In L.P. Steffe, P. Nesher, P. Cobb, G.A. Goldin, \& B. Greer (Eds.), Theories of mathematical learning (pp. 267-283). Mahwah, NJ: Erlbaum.

Yackel, E. \& Cobb, P. (1996). Sociomathematical norms, argumentation, and autonomy in mathematics. Journal for Research in Mathematics Education, 27 (4), 458-477.

Yackel, E. \& Hanna, G. (2003). Reasoning and proof. In J. W. Kilpatrick, G. Martin. \& D. Schifter. (Eds.), A research companion to Principles and Standards for school mathematics (pp 227-236). Reston, VA: National Council of Teachers of Mathematics

Zeidler, D. L., Lederman, N. G. \& Taylor, S. C. (1992). Fallacies and student discourse: Conceptualizing the role of critical thinking in science education. Science Education, 76(4), 437-450 